\title{
ADUBAÇÃO NITROGENADA E POTÁSSICA EM GOIABEIRAS 'PALUMA': II. EFEITO NO ESTADO NUTRICIONAL DAS PLANTAS ${ }^{1}$

\author{
DANIEL ANGELUCCI DE AMORIMㄴ HENRIQUE ANTUNES DE SOUZA ${ }^{3}$, \\ DANILO EDUARDO ROZANE ${ }^{4}$, RAFAEL MARANGONI MONTES ${ }^{5}$, WILLIAM NATALE ${ }^{6}$
}

RESUMO - A adequada adubação mineral de pomares de goiabeira, sob manejo intensivo, é fator preponderante na produtividade, e o acompanhamento do estado nutricional das plantas contribui para a eficiência desta prática agronômica. Objetivou-se pesquisar o efeito de diferentes doses de nitrogênio e potássio sobre o estado nutricional de goiabeiras 'Paluma'. O experimento foi conduzido em Vista Alegre do Alto-SP, em pomar irrigado, com sete anos de idade, manejado com podas de frutificação, durante quatro ciclos de produção consecutivos. O solo é o Argissolo Vermelho-Amarelo distrófico. O delineamento experimental foi em blocos ao acaso, com três repetições, em esquema fatorial com quatro doses de nitrogênio $(0 ; 0,5 ; 1,0$ e 2,0 kg planta-1 de N) e quatro de potássio $\left(0 ; 0,55 ; 1,1\right.$ e 2,2 $\mathrm{kg}^{-1}$ planta $^{-1}$ de $\left.\mathrm{K}_{2} \mathrm{O}\right)$. A adubação nitrogenada promoveu aumento nos teores foliares de $\mathrm{N}$ e $\mathrm{Mn}$ e decréscimo nos teores de $\mathrm{P}$ e $\mathrm{B}$, observados do segundo ao quarto ciclo produtivo. A adubação nitrogenada elevou os teores de $\mathrm{Ca}$ e $\mathrm{Mg}$, respectivamente, no segundo e terceiro ciclos. Com exceção do primeiro ciclo produtivo, os teores foliares de $\mathrm{K}$ e $\mathrm{Mn}$ aumentaram em função da adubação potássica, enquanto os teores de $\mathrm{Mg}$, no segundo e quarto ciclos, diminuíram em função dessa adubação.

Termos para indexação: Psidium guajava, análise foliar, macronutrientes, micronutrientes.

\section{NITROGEN AND POTASSIUM FERTILIZATION IN 'PALUMA' GUAVA TREES: II. EFFECT ON NUTRITIONAL STATUS OF THE PLANTS}

\begin{abstract}
The proper mineral fertilization of guava orchards under intensive management, is a major factor in productivity and monitoring the nutritional status of the plants contributes to the efficiency of this agronomic practice. The aim of this study was to investigate different doses of nitrogen and potassium in the nutritional status of guava 'Paluma'. The experiment was conducted at Vista Alegre do Alto, São Paulo, in a 7 year old irrigated orchard, managed with fruiting pruning during four consecutive growing seasons. The soil is a dystrophic Ultisol. The experimental design was randomized blocks, in factorial, with four nitrogen doses $\left(0,0.5,1\right.$ and $\left.2 \mathrm{~kg}_{\text {of N plant }}{ }^{-1}\right)$ and four of potassium $\left(0,0.55,1.1\right.$ and $2.2 \mathrm{~kg}_{\text {of }} \mathrm{K}_{2} \mathrm{O}$ plant $\left.\mathrm{t}^{-1}\right)$, with three replications. Nitrogen fertilization promoted increased levels of leaf $\mathrm{N}$ and $\mathrm{Mn}$ and the decrease in the levels of $\mathrm{P}$ and B; effects observed from the second to the fourth production cycle. Nitrogen fertilization increased the $\mathrm{Ca}$ and $\mathrm{Mg}$ levels, respectively, in the second and third cycle. Except for the first production cycle, $\mathrm{K}$ and $\mathrm{Mn}$ foliar concentrations increased with increasing potassium fertilization, whereas the levels of $\mathrm{Mg}$, in the second and the fourth cycle, decreased as a function of fertilization.
\end{abstract}

Index terms: Psidium guajava, leaf analysis, macronutrients, micronutrientes.

\footnotetext{
${ }^{1}$ (Trabalho 052-14). Recebido em: 13-02-2014. Aceito para publicação em: 19-07-2014.

${ }^{2}$ Pesquisador EPAMIG/Uberaba. Bolsista do CNPq. E-mail: daniel@epamig.br

${ }^{3}$ Pesquisador Embrapa Caprinos e Ovinos. E- mail: henrique.souza@embrapa.br

${ }^{4}$ Professor Assistente, Unesp/Registro. E-mail: danilorozane@registro.unesp.br

${ }^{5}$ Engenheiro Agrônomo, MSc., FCAV/Unesp/Jaboticabal. E-mail: rafammontes@yahoo.com.br

${ }^{6}$ Professor convidado. Université Laval - Canadá. E-mail: natale@fsaa.ulaval.ca
} 


\section{INTRODUÇÃO}

A goiabeira Paluma é cultivar produtiva e representa a maior parte dos pomares brasileiros da fruta (PEREIRA, 2008). Na última década, o manejo das áreas de plantio de goiabeiras foi modificado, evoluindo bastante, e, atualmente, essa frutífera é conduzida com podas mais intensas e irrigação, o que tem permitido, em função das épocas do ano, ciclos de colheita de frutos, em média, a cada oito meses (ROZANE et al., 2009)

A adubação nitrogenada aumenta a produtividade da goiabeira (NATALE et al., 1994; NATALE et al., 1995; TERAN et al., 1996; MACIEL et al., 2007; CARDOSO et al., 2011) e influencia sobre os teores foliares de $\mathrm{N}$ e Mn (NATALE et al., 1995; CAVALCANTE et al., 2008), podendo alterar também os teores de P (NATALE, 1993; CAVALCANTE et al., 2008), S (NATALE, 1993), bem como de $\mathrm{K}, \mathrm{Ca}$ e Mg (CAVALCANTE et al., 2008).

Algumas pesquisas indicam que a adubação potássica pode não influenciar sobre a produtividade da goiabeira; em contrapartida, aumenta os teores foliares de K (NATALE et al., 1996a; NATALE et al., 1996b), com efeitos indiretos sobre os teores de Mg e S (NATALE, 1993).

A folha completa é o material vegetal recomendado para a determinação dos teores de nutrientes em goiabeiras. Chetri et al.(1999) verificaram diferenças nos teores foliares de nutrientes, em função da cultivar e da fase fenológica da goiabeira, não encontrando diferenças nos teores foliares em função da posição cardeal da folha e da altura do ramo na copa das plantas.

A definição da posição da folha no ramo é outro fator importante e, nesse sentido, Natale et al. (2007) sugerem a coleta do terceiro par de folhas, na fase de pleno florescimento. Em geral, os teores de N, P e K diminuem com o aumento da idade da folha da goiabeira, enquanto os teores de $\mathrm{Ca}$ e $\mathrm{Mg}$ aumentam (KUMAR e PANDEY, 1979).

As sugestões de teores adequados de nutrientes em folhas de goiabeira são divergentes entre os trabalhos da literatura, possivelmente em função das diferentes épocas de coleta e de cultivares. Exemplificando para o nitrogênio, Natale et al. (2007) sugerem as faixas de teores foliares de 20 a $23 \mathrm{~g} \mathrm{~kg}^{-1}$ para a 'Paluma', enquanto Quaggio et al. (1997) e Oliveira (2004) sugerem a faixa adequada de $\mathrm{N}$ foliar para goiabeiras, sem especificar a cultivar, de 13 a 16 $\mathrm{g} \mathrm{kg}^{-1}$, sendo que as folhas foram coletadas em fases fenológicas posteriores à do pleno florescimento.

A adequada adubação mineral da goiabeira é fator preponderante na produtividade dos pomares, e o acompanhamento do estado nutricional das plantas contribui para melhorar a eficiência desta prática agronômica. $\mathrm{O}$ presente trabalho objetivou avaliar o estado nutricional de goiabeiras 'Paluma', submetidas à adubação nitrogenada e à potássica.

\section{MATERIAL E MÉTODOS}

O experimento foi conduzido em pomar de goiabeiras 'Paluma', com sete anos, espaçadas de $7 \mathrm{x}$ 5 metros, sob sistema de irrigação por microaspersão. O pomar pertence à Indústria de Polpas e Conservas VAL Ltda., em Vista Alegre do Alto-SP. Segundo a classificação de Köppen, o clima local é do tipo Cwa subtropical com inverno curto, moderado e seco, verão quente e chuvoso, caracterizando duas estações climáticas distintas.

O solo é Argissolo Vermelho-Amarelo distrófico (EMBRAPA, 2006). A área foi corrigida com calcário, noventa dias antes da instalação do experimento, aplicado sobre o solo sem incorporação. Foram realizadas coletas de solo para determinar as propriedades químicas tanto na projeção da copa das plantas (a 1,75 $\mathrm{m}$ do tronco) quanto na entrelinha do pomar (centro da rua), nas camadas de $0,0-0,2$ e de 0,2-0,4 m, caracterizando o estado inicial do solo. As metodologias de análises utilizadas foram as propostas por Raij et al. (2001), com exceção da análise de sulfato $\left(\mathrm{S}_{-} \mathrm{SO}_{4}^{-2}\right)$ realizada conforme metodologia de Vitti (1989) (Tabela 1).

$\mathrm{O}$ delineamento experimental utilizado foi o de blocos ao acaso, em esquema fatorial $4 \times 4$, sendo quatro doses de nitrogênio $(0 ; 0,5 ; 1$ e $2 \mathrm{~kg}$ de $\mathrm{N}$ planta $\left.^{-1}\right)$ e quatro doses de potássio $(0 ; 0,55 ; 1,1$ e 2,2 $\mathrm{kg}$ de $\mathrm{K}_{2} \mathrm{O}$ planta $^{-1}$ ), com três repetições. As parcelas experimentais foram constituídas de cinco plantas, sendo as três goiabeiras centrais consideradas úteis para as avaliações.

O experimento foi conduzido por três ciclos consecutivos de produção, sendo considerado como ciclo o período da poda até o final da colheita. O primeiro ciclo foi de fevereiro a novembro de 2009 (outono/primavera), perfazendo o total de 268 dias. O segundo foi de dezembro de 2009 até agosto de 2010 (verão/inverno), com 253 dias. O terceiro ciclo de produção foi de setembro de 2010 até abril de 2011(primavera/outono), com 238 dias. Apresentaram-se, também, dados do início do quarto ciclo, compreendido da poda até a coleta de folhas, para fins de avaliações do estado nutricional. A poda do quarto ciclo foi em junho de 2011.

As fontes dos nutrientes foram os fertilizantes ureia $(45 \% \mathrm{~N})$ e cloreto de potássio $\left(60 \% \mathrm{~K}_{2} \mathrm{O}\right)$, 
granulados. Os fertilizantes foram distribuídos equitativamente na superfície do solo, ao redor de cada planta, na faixa entre 1,5 e 2,0 metros a partir do tronco. As doses foram parceladas três vezes no primeiro ciclo, a cada 30 dias, e em quatro vezes nos outros ciclos, a cada 25 dias, tendo início na fase de pré-florescimento.

As adubações com fósforo (superfosfato simples) foram estipuladas conforme as concentrações de P no solo e a produtividade média do pomar, seguindo as recomendações de Natale et al. (2007), aplicadas uma única vez, a cada ciclo de produção, juntamente com o primeiro parcelamento dos adubos $\mathrm{N}$ e K. As adubações com zinco (sulfato de zinco) e boro (ácido bórico) foram realizadas juntamente com as pulverizações de herbicidas.

O pomar foi irrigado por sistema de microaspersão, com um microaspersor (tipo bailarina) por goiabeira, com raio de ação de $2,4 \mathrm{~m}$ e vazão de 36 litros por hora. A umidade do solo foi monitorada por tensiometria, na camada de $0,0-0,2$ m ( $60 \%$ da capacidade de campo).

O manejo do pomar, em relação ao controle das doenças, pragas e plantas daninhas, foi realizado seguindo as recomendações técnicas para a produção de goiabas para a indústria (PEREIRA, 1995). As podas foram realizadas conforme Rozane et al. (2009), eliminando-se os ramos mais grossos das plantas, permitindo que suas copas ficassem com a forma de taça aberta. Os ramos mais finos foram encurtados, deixando-se, em média, de 2 a 5 gemas. Todo o material resultante da poda foi colocado nas entrelinhas do pomar e triturado com auxílio de roçadeira.

Foram coletados, por parcela, 12 pares de folhas com pecíolo, recém-maduras, posicionadas no terceiro par, a partir da extremidade do ramo, no período de pleno florescimento (NATALE et al., 2007). As amostras foram lavadas e secas em estufa a $65 \pm 5^{\circ} \mathrm{C}$, e analisadas para a determinação dos teores de N, P, K, Ca, Mg, S, B, Cu, Fe, Mn e Zn, segundo metodologia de Bataglia et al. (1983).

Os resultados foram submetidos à análise de variância com a aplicação do teste $\mathrm{F}$ e, quando significativos, realizou-se a análise de regressão polinomial. Para a realização das análises estatísticas, foi utilizado o programa SISVAR (FERREIRA, 2011).

\section{RESULTADOS E DISCUSSÃO}

No primeiro ciclo produtivo, os teores dos nutrientes nas folhas não diferiram em função dos tratamentos, provavelmente devido à proximidade entre a primeira aplicação dos fertilizantes e a coleta do material vegetal, que foi de apenas 12 dias.

A adubação nitrogenada influenciou sobre os teores foliares de $\mathrm{N}$, com aumento linear do elemento no segundo e quarto ciclos produtivos, enquanto para o terceiro ciclo, a equação quadrática foi a que melhor se ajustou (Figura 1a).

Em pesquisa com goiabeiras 'Paluma' jovens, em pomar não irrigado, durante três safras, observouse aumento nos teores foliares de $\mathrm{N}$ em função da adubação nitrogenada no segundo e terceiro anos, variando, respectivamente, de 17 a 20 e de 18 a $23 \mathrm{~g}$ $\mathrm{kg}^{-1}$ (NATALE et al., 1995). Cavalcante et al. (2008), trabalhando com pomar fertirrigado de goiabeiras 'Paluma' recém-plantadas, verificaram aumentos lineares nos teores foliares de $\mathrm{N}$ em função do incremento na adubação com sulfato de amônio; os valores estimados, em função da equação, variaram de 14,8 a $22,3 \mathrm{~g} \mathrm{~kg}^{-1}$. No entanto, esses autores avaliaram somente um ciclo de produção.

De acordo com resultados relativos à adubação de nitrogênio e seu efeito na produtividade, encontraram-se, para alcançar a produção relativa (PR de 95\%) nos três primeiros ciclos produtivos, respectivamente, 0,$73 ; 0,87$ e $0,85 \mathrm{~kg}$ planta $^{-1}$, sendo as doses para alcançar a produção máxima (PM) iguais a 1,36; 1,37 e $1,28 \mathrm{~kg}$ de $\mathrm{N}_{\text {planta }}{ }^{-1}$. Com as doses estimadas para alcançar a $\mathrm{PR}=95 \%$ e a PM, definiram-se as seguintes faixas de teores foliares de N: 20,6 a 21,8 $\mathrm{g} \mathrm{kg}^{-1}$ e 20,6 a 21,6 $\mathrm{g} \mathrm{kg}^{-1}$, respectivamente, para o segundo e o terceiro ciclos. Esses teores estão dentro da faixa sugerida por Natale et al. (2007) para 'Paluma', que é de 20 a $23 \mathrm{~g} \mathrm{~kg}^{-1}$, e próximos aos encontrados por Souza et al. (2013), que trabalharam com normas DRIS para goiabeira 'Paluma' irrigada e sugeriram como faixa adequada para $\mathrm{N}$ os valores de 18 a $21 \mathrm{~g} \mathrm{~kg}^{-1}$ e nível crítico de $19 \mathrm{~g} \mathrm{~kg}^{-1}$. Entretanto, os valores encontrados são superiores àqueles indicados para goiabeiras por Quaggio et al.(1997) e Oliveira (2004), que sugerem teores de 13 a $16 \mathrm{~g} \mathrm{~kg}^{-1}$ indicados em amostragem de folhas em fases fenológicas posteriores à do pleno florescimento.

As parcelas-controle (zero de $\mathrm{N}$ ) tiveram reduções de produtividade de $24 ; 38$ e $43 \%$, respectivamente, no primeiro, segundo e terceiro ciclos, enquanto os teores foliares de $\mathrm{N}$ nas goiabeiras foram 16,$1 ; 17,6$ e $16,4 \mathrm{~g} \mathrm{~kg}^{-1}$, para cada um dos anos. Esses teores são considerados deficientes segundo Natale et al. (2007) e Souza et al. (2013), porém estariam na faixa adequada de acordo com Quaggio et al. (1997) e Oliveira (2004). Por outro lado, o uso das doses mais elevadas $\left(2,0 \mathrm{~kg}\right.$ planta $^{-1}$ de $\mathrm{N}$ ) proporcionou teores foliares de 22,9; $21,7 \mathrm{e}$ 
$20,1 \mathrm{~g} \mathrm{~kg}^{-1}$, respectivamente, no segundo, terceiro e quarto ciclos. Pode-se inferir, apesar da elevada dose, que não houve consumo de luxo de nitrogênio, de acordo com as indicações de Natale et al. (2007) para 'Paluma'.

A adubação nitrogenada provocou redução nos teores foliares de $\mathrm{P}$, representada por equações quadráticas (Figura 1b). Com a cultivar 'Rica', durante três safras, Natale (1993) constatou, apenas no segundo ano, decréscimos no teor foliar de $\mathrm{P}$ em função do aumento das doses de N.

Todas as parcelas experimentais receberam a mesma adubação fosfatada, mantendo-se o solo com concentrações altas, acima de $31 \mathrm{mg} \mathrm{dm}^{-3}$, segundo indicação de Raij et al. (1997). Natale et al. (2001) verificaram que as adubações com fósforo não promoveram modificações nos teores de $\mathrm{P}$ das folhas de goiabeiras 'Paluma'. Portanto, a priori, os teores foliares de $\mathrm{P}$ não estão diretamente ligados às concentrações de $\mathrm{P}$ no solo, mas, sim, a um efeito da interação com a adubação nitrogenada, conforme indicado na Figura 1b. Isso pode estar relacionado à maior absorção de nitrogênio em relação ao fósforo, ou devido ao efeito de diluição (ANDRADE et al., 2000), provocado pelo crescimento mais rápido dos ramos das plantas adubadas com maiores doses de N.

Com as doses de $\mathrm{N}$ estimadas para alcançar a $\mathrm{PR}=95 \%$ e a PM, os teores foliares de $\mathrm{P}$ ficaram nas faixas de 1,5-1,4 e 1,2-1,1 $\mathrm{g} \mathrm{kg}^{-1}$, respectivamente, no segundo e terceiro ciclos produtivos. Os teores de $\mathrm{P}$ no segundo ciclo, bem como o teor foliar médio de fósforo no primeiro ciclo $\left(1,6 \mathrm{~g} \mathrm{~kg}^{-1}\right)$, estão dentro da faixa de valores considerados adequados (1,4 a

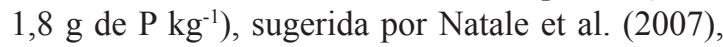
para 'Paluma', e, também, da faixa de 1,4 a 1,6 g $\mathrm{kg}^{-1}$, sugerida por Quaggio et al. (1997) e Oliveira (2004), para goiabeiras em geral. Souza et al. (2013) sugerem para goiabeira 'Paluma' irrigada teores foliares de $\mathrm{P}$ de 1,5-1,7 $\mathrm{g} \mathrm{kg}^{-1}$ e nível crítico de 1,6 $\mathrm{g} \mathrm{kg}^{-1}$. Por outro lado, os teores no terceiro ciclo produtivo apresentaram-se inferiores a estas faixas.

Com relação ao cálcio, houve influência da adubação nitrogenada no terceiro ciclo, ocorrendo incremento de $\mathrm{Ca}$ em função das doses de $\mathrm{N}$, sendo a variação de 6,0 a 6,9 $\mathrm{g} \mathrm{kg}^{-1}$ (Figura 1c). Em contraste, a análise de solo, ao final do segundo ciclo produtivo, revelou valores de $\mathrm{Ca}$ que diminuíram, em função do aumento das doses de $\mathrm{N}$, de 25 a $15 \mathrm{mmol} \mathrm{dm}^{-3}$ na camada de 0,0-0,2 $\mathrm{m}$ e, de 11 a $7 \mathrm{mmol}_{\mathrm{c}} \mathrm{dm}^{-3}$ na camada de 0,2-0,4 m.

Natale (1993), trabalhando em pomares jovens de goiabeiras 'Paluma' durante três safras, não verificou influência da adubação nitrogenada sobre os teores foliares de $\mathrm{Ca}$, sendo observados valores entre 7,9 e 9,9 $\mathrm{g} \mathrm{kg}^{-1}$. Por outro lado, Cavalcante et al. (2008), aplicando via irrigação doses semanais de sulfato de amônio, cujos tratamentos foram controle: 1,$25 ; 2,50 ; 3,90$ e 5,00 $\mathrm{kg} \mathrm{ha}^{-1}$, observaram aumento nos teores foliares de $\mathrm{Ca}$ em goiabeira 'Paluma' até a dose de 2,5 $\mathrm{kg} \mathrm{ha}^{-1}$ semana $^{-1}$, com posterior decréscimo, variando de 8,7 a $11,7 \mathrm{~g} \mathrm{~kg}^{-1}$ os teores foliares de $\mathrm{Ca}$ observados.

Os teores médios de $\mathrm{Ca}$ no primeiro e segundo ciclos foram, respectivamente, 9,5 e 7,9 g $\mathrm{kg}^{-1}$, estando, portanto, dentro da faixa considerada adequada para 'Paluma', que é de 7 a $11 \mathrm{~g} \mathrm{~kg}^{-1}$ (NATALE et al., 2007); entretanto, os teores de Ca no terceiro ciclo, bem como o teor médio no quarto ciclo (6,9 $\left.\mathrm{g} \mathrm{kg}^{-1}\right)$, estão abaixo do adequado. Quaggio et al. (1997) e Oliveira (2004) sugerem, como adequados, teores de $\mathrm{Ca}$ ainda mais altos, de 9 a $15 \mathrm{~g} \mathrm{~kg}^{-1}$. Souza et al. (2013) indicaram como faixa adequada e nível crítico para $\mathrm{Ca}$, em goiabeira 'Paulma' irrigada, valores de 8-11 e $9 \mathrm{~g} \mathrm{~kg}^{-1}$, respectivamente. Vale ressaltar que as concentrações de Ca no solo se mantiveram com valores altos (dados não apresentados), segundo Raij et al. (1997), durante o período experimental, apesar do decréscimo em função da adubação nitrogenada.

Os teores foliares de $\mathrm{Mg}$ foram influenciados pela adubação nitrogenada apenas no segundo ciclo. Observou-se aumento do teor foliar do nutriente até a dose estimada de 1,2 kg planta $^{-1}$ de $\mathrm{N}$, com posterior decréscimo; os teores nas folhas variaram de 1,96 a 2,13 $\mathrm{g} \mathrm{kg}^{-1}$ (Figura 1c). Em contrapartida, as concentrações de $\mathrm{Mg}$ no solo diminuíram em função das adubações nitrogenadas e, na avaliação realizada no final do primeiro ciclo (início do segundo ciclo), os valores estiveram na faixa de 11 a $8 \mathrm{mmol}_{\mathrm{c}} \mathrm{dm}^{-3}$ na camada de $0,0-0,2 \mathrm{~m}$, e de 6 a $4 \mathrm{mmol}_{\mathrm{c}} \mathrm{dm}^{-3}$ na camada de $0,2-0,4 \mathrm{~m}$, considerados, respectivamente, valores alto e médio (RAIJ et al., 1997).

Em três safras avaliadas em goiabeiras cultivar Rica, Natale (1993) verificou, apenas no último ciclo, decréscimos nos teores foliares de $\mathrm{Mg}$, em função da adubação nitrogenada. Este efeito não foi observado para a cultivar Paluma, que apresentou teores foliares de $\mathrm{Mg}$ variando de 3,4 a 4,2 $\mathrm{g} \mathrm{kg}^{-1}$ (NATALE et al., 1995). Cavalcante et al. (2008) observaram, também, redução dos teores foliares de Mg em função da adubação sulfato-nitrogenada, com variaçao de 3,9 a 3,4 $\mathrm{g} \mathrm{kg}^{-1}$. Ressalta-se, porém, que ambas as pesquisas foram conduzidas com plantas jovens.

Os teores foliares médios de magnésio, no primeiro, terceiro e quarto ciclos produtivos, foram, respectivamente, 2,12; 1,99 e $2,14 \mathrm{~g} \mathrm{~kg}^{-1}$. Assim, os teores foliares de $\mathrm{Mg}$ variaram pouco 
nas quatro amostragens realizadas, enquanto as concentrações de $\mathrm{Mg}$ no solo decresceram com o decorrer dos ciclos (dados não apresentados). Os valores iniciais considerados altos (RAIJ et al., 1997), descritos na Tabela 1, diminuíram em função da adubação nitrogenada, para 6 a $9 \mathrm{mmol}_{\mathrm{c}} \mathrm{dm}^{-3} \mathrm{na}$ camada superficial do solo e para 3 a $6 \mathrm{mmol}_{\mathrm{c}} \mathrm{dm}^{-3}$ na subsuperfície, ao final do terceiro ciclo produtivo.

Em todos os ciclos, os teores foliares de $\mathrm{Mg}$ estão abaixo da faixa adequada para 'Paluma', de 3,4 a 4,0 $\mathrm{g} \mathrm{kg}^{-1}$ (NATALE et al., 2007) ou 2,4 a 4,0 $\mathrm{g} \mathrm{kg}^{-1}$ (QUAGGIO et al., 1997; OLIVEIRA, 2004), além de serem inferiores aos encontrados nos trabalhos de Natale et al. (1995) e Cavalcante et al. (2008). Por outro lado, seriam considerados adequados quando comparados ao trabalho de Souza et al. (2013) com goiabeiras 'Paluma' irrigadas, os quais, utilizando a metodologia DRIS, definiram como faixa adequada para $\mathrm{Mg}$ os valores de $1,8-2,5 \mathrm{~g} \mathrm{~kg}^{-1}$ e nível crítico de $2,2 \mathrm{~g} \mathrm{~kg}^{-1}$.

Os teores de $\mathrm{S}$ nas folhas coletadas no segundo e quarto ciclos diminuíram em função da adubação com $\mathrm{N}$, variando, respectivamente, de 2,64 a 2,09 $\mathrm{g} \mathrm{kg}^{-1}$ e de 2,55 a 2,08 $\mathrm{g} \mathrm{kg}^{-1}$ (Figura 1d). No primeiro e terceiro ciclos, não ocorreu este efeito do $\mathrm{N}$, e as folhas apresentaram teores médios de $\mathrm{S}$ de 2,34 e 2,17 $\mathrm{g} \mathrm{kg}^{-1}$, respectivamente. Com as doses de $\mathrm{N}$ estimadas para alcançar a $\mathrm{PR}=95 \%$ e a $\mathrm{PM}$, os teores foliares de $\mathrm{S}$ no segundo ciclo foram de 2,17-2,06 $\mathrm{g} \mathrm{kg}^{-1}$, abaixo do considerado adequado para a cultivar, que é de 2,5-3,5 $\mathrm{g} \mathrm{kg}^{-1}$ (NATALE et al., 2007) e 2,5-2,9 $\mathrm{g} \mathrm{kg}^{-1}$ (SOUZA et al., 2013). Assim como para os teores de $\mathrm{Mg}$, os valores de $\mathrm{S}$ também estão abaixo dos descritos nos trabalhos de Natale et al.(1995) e Cavalcante et al. (2008), que não encontraram influência da adubação nitrogenada sobre os teores foliares de enxofre.

As concentrações de B no solo estavam inicialmente baixas (RAIJ et al., 1997), conforme descritas na Tabela 1, e mantiveram-se assim nos três ciclos avaliados, apesar das adubações realizadas com ácido bórico. Por outro lado, a adubação nitrogenada aumentou as concentrações de $\mathrm{B}$ do solo. As equações $\mathrm{y}_{1}=0,021 \mathrm{~N}+0,180\left(\mathrm{R}^{2}=0,76^{*}\right)$, $\mathrm{y}_{2}=0,022 \mathrm{~N}+0,153\left(\mathrm{R}^{2}=0,83^{* *}\right)$ e $\mathrm{y}_{3}=-0,027 \mathrm{~N}^{2}$ $+0,080 \mathrm{~N}+0,166\left(\mathrm{R}^{2}=0,99 * *\right)$ representam as concentrações de $\mathrm{B}\left(\mathrm{em} \mathrm{mg} \mathrm{\textrm {dm } ^ { - 3 }}\right.$ ) da camada de solo de 0,0-0,2 m, em função das doses de $\mathrm{N}$ (kg planta $\left.{ }^{-1}\right)$, respectivamente, para o primeiro, segundo e terceiro ciclos. Apesar desse aumento, os teores foliares de $\mathrm{B}$ diminuíram em função da adubação (Figura 1e). Em contraste, Cavalcante et al. (2008) não observaram, em goiabeiras 'Paluma', efeito da adubação nitrogenada sobre os teores foliares de B.
O teor foliar médio de B no primeiro ciclo foi de $42 \mathrm{mg} \mathrm{kg}^{-1}$. Aplicando as doses indicadas de $\mathrm{N}$, os teores foliares no segundo ciclo foram de 26 a $24 \mathrm{mg} \mathrm{kg}^{-1}$, portanto próximos à faixa de teores considerados adequados de 20 a $25 \mathrm{mg} \mathrm{kg}^{-1}$ (NATALE et al., 2007) e 26-38 g kg-1 (SOUZA et al., 2013) para a 'Paluma'. No terceiro ciclo, os teores foram de 15 a $14 \mathrm{mg} \mathrm{kg}^{-1}$, abaixo do adequado, sendo que os teores do quarto ciclo se apresentaram ainda mais baixos, conforme indicado na Figura 1e.

A adubação nitrogenada reduziu o pH do solo e elevou a disponibilidade de $\mathrm{Mn}$. As equações $\mathrm{y}_{1}=$ $2,455 \mathrm{~N}+13,05\left(\mathrm{R}^{2}=0,71 * *\right) ; \mathrm{y}_{2}=3,33 \mathrm{~N}+11,42$ $\left(\mathrm{R}^{2}=0,89 * *\right)$, e $\mathrm{y}_{3}=-4,178 \mathrm{~N}^{2}+9,604 \mathrm{~N}+12,31\left(\mathrm{R}^{2}\right.$ $=0,82 * *)$ representam as concentrações de $\mathrm{Mn}$ (em $\mathrm{mg} \mathrm{dm}^{-3}$ ) da camada de solo de 0,0-0,2 m, em função das doses de $\mathrm{N}$, respectivamente, para o primeiro, segundo e terceiro ciclos.

Os teores foliares de Mn aumentaram linearmente com a adubação nitrogenada (Figura 1f). Corroborando o verificado nos trabalhos de Natale (1993), a 'Rica' e a 'Paluma', que apresentaram aumento nos teores foliares de Mn em função da adubação com N, pode-se concluir que este efeito é muito característico para a goiabeira. Com as doses de $\mathrm{N}$ sugeridas para alcançar a $\mathrm{PR}=95 \%$ e $\mathrm{PM}$, os teores foliares de Mn ficaram nas faixas de 65 a 78 e de 87 a $104 \mathrm{mg} \mathrm{kg}^{-1}$, respectivamente, no segundo e terceiro ciclos produtivos; no primeiro ciclo, observaram-se valores médios de $57 \mathrm{mg} \mathrm{kg}^{-1}$. Estes teores encontram-se dentro ou pouco acima da faixa sugerida como adequada por Natale et al. (2007), que é de 40 a $80 \mathrm{mg} \mathrm{kg}^{-1}$, ou da faixa de 53$101 \mathrm{~g} \mathrm{~kg}^{-1}$, sugerida por Souza et al. (2013). Quando comparados às condições do Cerrado, esses teores estão muito abaixo da faixa de 202 a $398 \mathrm{mg} \mathrm{kg}^{-1}$, sugerida por Oliveira (2004).

A adubação potássica não influenciou na produtividade da goiabeira, mas promoveu aumento linear dos teores foliares desse nutriente, exceto no primeiro ciclo produtivo (Figura 2a). Resultados semelhantes foram encontrados por Natale (1993) para 'Paluma' e 'Rica' em São Paulo, o que sinaliza, em termos nutricionais, um acúmulo do nutriente em resposta da goiabeira à adubação potássica.

Quaggio et al. (1997) e Oliveira (2004) sugerem, como faixa adequada de teores de $\mathrm{K}$ em folhas de goiabeiras, de 13 a $16 \mathrm{~g} \mathrm{~kg}^{-1}$. Avaliando as equações da Figura $2 \mathrm{a}$, verifica-se que o teor foliar de $\mathrm{K}$, nos quatro ciclos avaliados, nunca esteve abaixo de $13 \mathrm{~g} \mathrm{~kg}^{-1}$, mesmo quando as plantas não receberam adubação potássica.

Natale et al. (2007) sugerem como adequados, para a 'Paluma', os teores foliares de K de 14 a 
$17 \mathrm{~g} \mathrm{~kg}^{-1}$. Dessa forma, doses de 0,66 e $0,13 \mathrm{~kg}$ $\mathrm{K}_{2} \mathrm{O}$ planta $^{-1}$, respectivamente, para o terceiro e quarto ciclos, seriam suficientes para as goiabeiras apresentarem teores foliares de $\mathrm{K}$ de $14 \mathrm{~g} \mathrm{~kg}^{-1}$. Assim, para os dois primeiros ciclos, não seriam necessárias adubações potássicas para alcançar o teor mínimo de K sugerido por esses autores.

Souza et al. (2013) sugerem a faixa adequada de teores foliares e $\mathrm{K}$ de $15-17 \mathrm{~g} \mathrm{~kg}^{-1}$ e de $16 \mathrm{~g} \mathrm{~kg}^{-1}$ como nível crítico para o teor de $\mathrm{K}$ em goiabeira 'Paluma' irrigada.

Nas condições do Semiárido do Ceará, Cardoso et al. (2010) testaram 16 combinações de NPK com a 'Paluma', em uma safra apenas, sendo que as doses de $\mathrm{K}_{2} \mathrm{O}$ variaram de 0,029 a $0,533 \mathrm{~kg}$ planta $^{-1}$. Os autores não encontraram diferenças significativas nos teores foliares de $\mathrm{K}$, que variaram de 15,5 a 20,5 $\mathrm{g} \mathrm{kg}^{-1}$, cuja média foi de $17,5 \mathrm{~g} \mathrm{~kg}^{-1} \mathrm{e}$, portanto, superior às faixas sugeridas acima.

No presente trabalho, não se observou efeito da adubação nitrogenada sobre os teores foliares de $\mathrm{K}$, como mostrado por Cavalcante et al. (2008) para as condições de Clima quente e úmido da Paraíba. Esses autores verificaram que os teores foliares de $\mathrm{K}$ aumentaram linearmente em função das doses de $\mathrm{N}$, variando de 14,3 a 19,7 $\mathrm{g} \mathrm{kg}^{-1}$. Alguns desses valores também são superiores aos propostos como adequados para as condições de São Paulo (NATALE et al., 2007; QUAGGIO et al.,1997; SOUZA et al., 2013).
Os teores foliares de $\mathrm{Mg}$ diminuíram linearmente, em função da adubação potássica, nas avaliações realizadas no segundo e quarto ciclos (Figura 2b), o que não foi verificado nos outros dois ciclos. Natale (1993), estudando três safras em pomar de 'Paluma' recém-implantado, verificou diminuição dos teores foliares de $\mathrm{Mg}$ em função da adubação potássica apenas no segundo ano, sendo o mesmo efeito observado para a goiabeira 'Rica' no terceiro ano. Este efeito pode ser devido à absorção competitiva entre esses dois elementos, sendo que cátions como o $\mathrm{K}^{+} \mathrm{e} \mathrm{o} \mathrm{Ca}^{2+}$ competem efetivamente com $\mathrm{Mg}^{2+}$, reduzindo sua absorção, por exemplo, quando potássio e calcário são aplicados (MARSCHNER, 1995). Em plantas de milho, Vilela e Bull (1999) verificaram menores teores foliares de $\mathrm{Ca}$ e Mg nos tratamentos com maiores doses de K aplicados ao solo.

Os teores foliares de Mn aumentaram de forma linear em função da adubação potássica, com exceção do primeiro ciclo produtivo (Figura 2c), apesar de esta adubação não ter influenciado nas concentrações de Mn no solo. Por outro lado, Natale (1993) não observou efeito da adubação potássica sobre os teores foliares de Mn em goiabeiras.

Por fim, destaca-se que a interação $\mathrm{N}$ x K não foi significativa para os teores foliares dos nutrientes em qualquer dos ciclos.

TABELA 1 - Propriedades químicas do solo nas camadas de 0,0-0,2 e 0,2-0,4 m de profundidade, na faixa adubada (linha) e na entrelinha das plantas, antes da instalação do experimento.

\begin{tabular}{|c|c|c|c|c|c|c|c|c|}
\hline Amostra & pH* & М.O. & $\mathbf{P} * *$ & $\mathbf{K}$ & $\mathrm{Ca}$ & Mg & $\mathbf{H}+\mathbf{A l}$ & SB \\
\hline Linha & & $\mathrm{g} \mathrm{dm}^{-3}$ & $\mathrm{mg} \mathrm{dm}^{-3}$ & \multicolumn{5}{|c|}{---------------mmol $\mathrm{dm}^{-3}$---------------- } \\
\hline $0,0-0,2 \mathrm{~m}$ & 5,9 & 11 & 19 & 2,2 & 29 & $14^{c}$ & 12 & 45,2 \\
\hline $0,2-0,4 \mathrm{~m}$ & 5,4 & 9 & 7 & 2,0 & 22 & 9 & 16 & 33,0 \\
\hline \multicolumn{9}{|l|}{ Entrelinha } \\
\hline $0,0-0,2 \mathrm{~m}$ & 6,0 & 12 & 13 & 2,9 & 29 & 15 & 11 & 46,9 \\
\hline \multirow[t]{2}{*}{$0,2-0,4 \mathrm{~m}$} & 5,7 & 9 & 7 & 2,7 & 24 & 9 & 13 & 35,7 \\
\hline & $\mathbf{T}$ & $\mathrm{V}$ & B & $\mathrm{Cu}$ & $\mathrm{Fe}$ & Mn & Zn & $\mathrm{S}_{-\mathrm{SO}_{4}^{-2}}^{-2}$ \\
\hline Linha & $\mathrm{mmol}_{\mathrm{c}} \mathrm{dm}^{-3}$ & $\%$ & \multicolumn{6}{|c|}{ 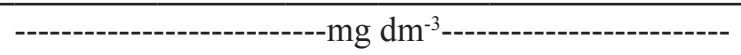 } \\
\hline $0,0-0,2 \mathrm{~m}$ & 57,2 & 79 & 0,17 & 11,9 & 13 & 11,9 & 0,4 & 2 \\
\hline $0,2-0,4 \mathrm{~m}$ & 49,0 & 67 & 0,16 & 4,4 & 12 & 11,2 & 0,3 & 3 \\
\hline \multicolumn{9}{|l|}{ Entrelinha } \\
\hline $0,0-0,2 \mathrm{~m}$ & 57,9 & 81 & 0,34 & 14,7 & 12 & 12,6 & 0,4 & 3 \\
\hline $0,2-0,4 \mathrm{~m}$ & 48,7 & 73 & 0,16 & 4,0 & 10 & 10,6 & 0,3 & 4 \\
\hline
\end{tabular}

*pH $\left(\mathrm{CaCl}_{2}\right) ; *$ P (resina) 


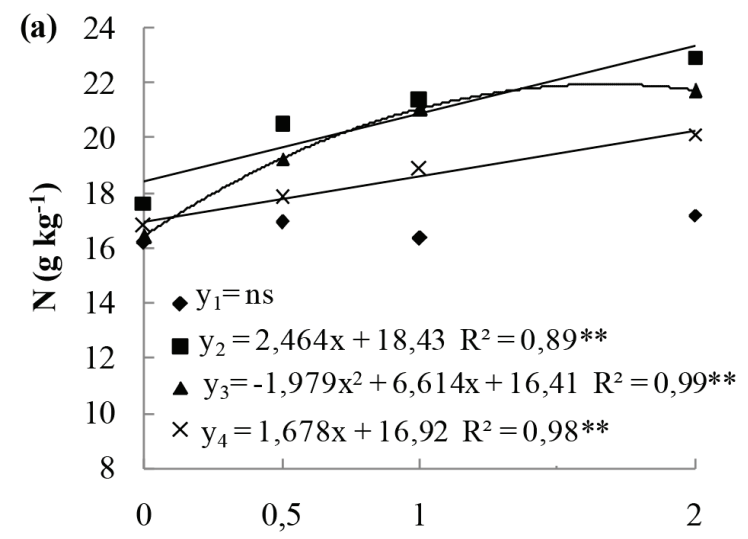

Doses de N (kg planta $\left.{ }^{-1}\right)$

(c)

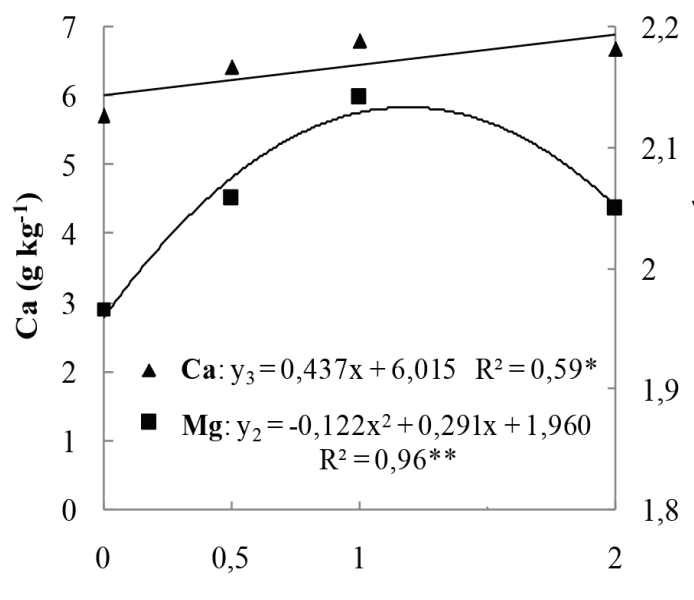

Doses de N (kg planta $\left.{ }^{-1}\right)$

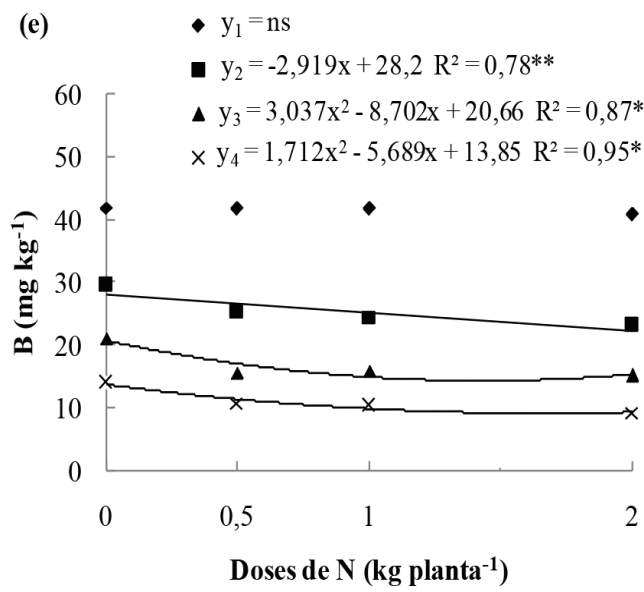

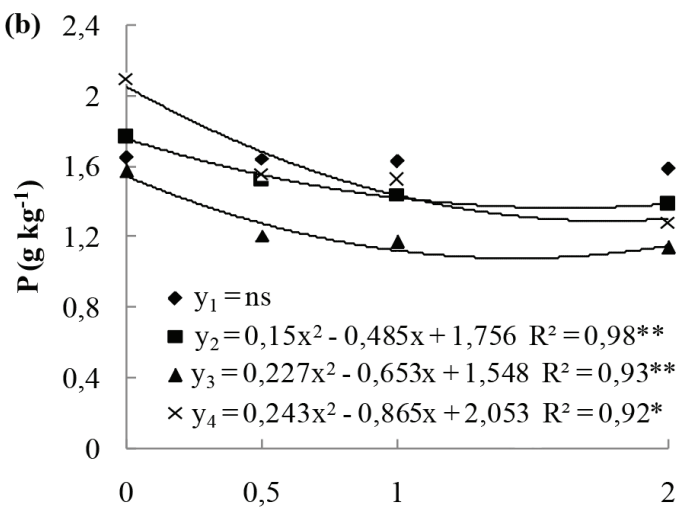

Doses de N (kg planta $\left.{ }^{-1}\right)$
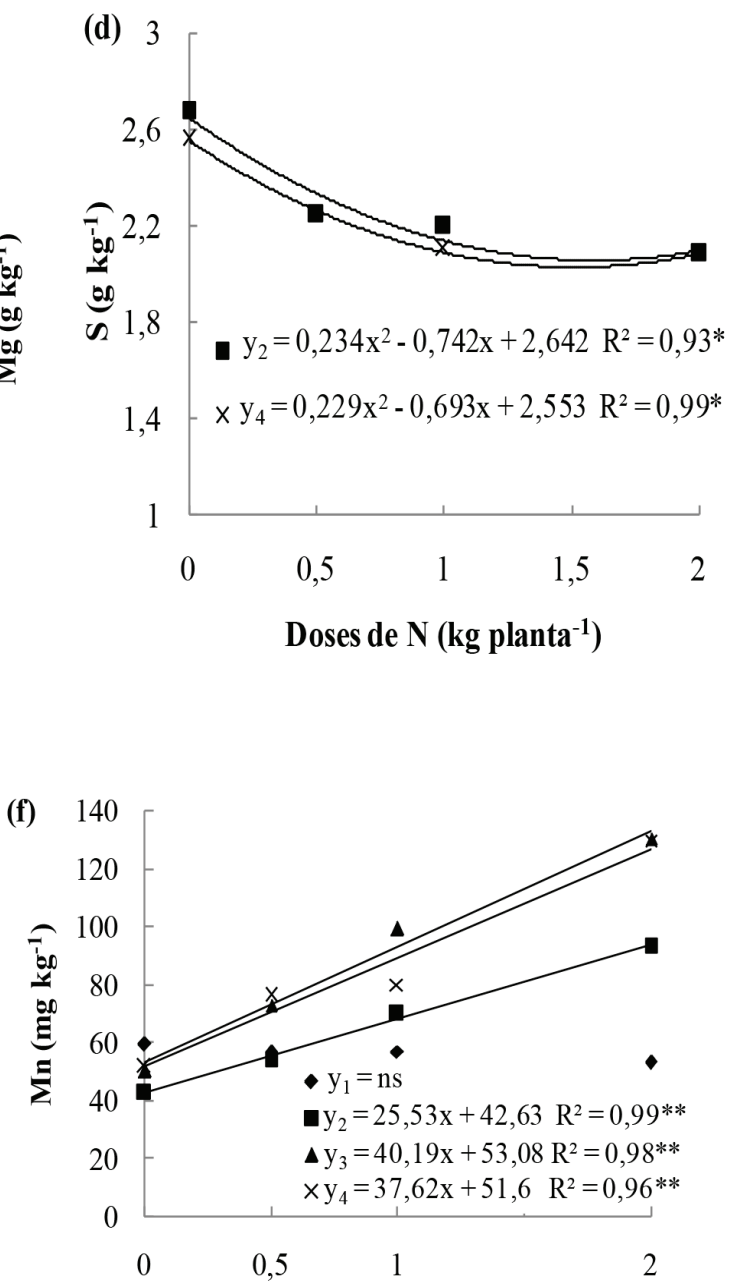

Doses de N (kg planta $\left.{ }^{-1}\right)$

FIGURA1- Teores de N (a), P (b), Ca e Mg (c), S (d), B (e) e Mn (f) em folhas de goiabeiras, em função da adubação nitrogenada. $\mathrm{y}_{1} \mathrm{y}_{2,} \mathrm{y}_{3}$ e $\mathrm{y}_{4}$ representam as equações para o primeiro, segundo, terceiro e quarto ciclos de produção, respectivamente. 

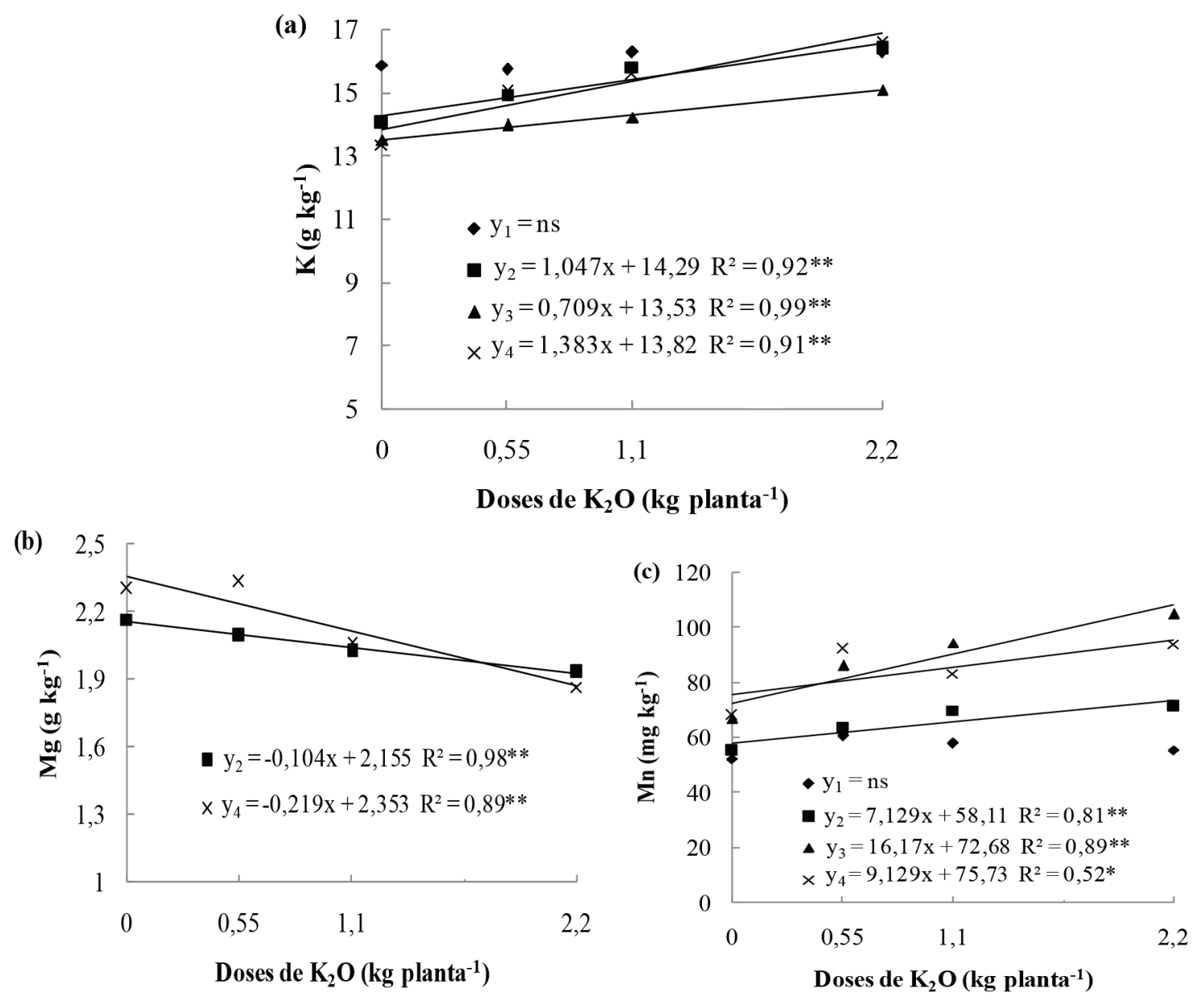

FIGURA 2- Teores de $\mathrm{K}$ (a), $\mathrm{Mg}$ (b) e $\mathrm{Mn}$ (c) em folhas de goiabeiras, em função da adubação potássica. $\mathrm{y}_{1,} \mathrm{y}_{2,} \mathrm{y}_{3}$ e $\mathrm{y}_{4}$ representam as equações para o primeiro, segundo, terceiro e quarto ciclos de produção, respectivamente. 


\section{CONCLUSÕES}

A adubação nitrogenada promoveu aumento nos teores foliares de $\mathrm{N}$ e $\mathrm{Mn}$, e decréscimos nos de $\mathrm{P}, \mathrm{S}$ e $\mathrm{B}$.

A adubação potássica promoveu aumento nos teores foliares de $\mathrm{K}$ e $\mathrm{Mn}$, e decréscimo nos teores de Mg.

A interação $\mathrm{N}$ x K não apresentou efeitos significativos sobre os teores foliares de nutrientes.

\section{AGRADECIMENTOS}

À FCAV/UNESP e à EPAMIG pela oportunidade de realização do doutorado. À FAPEMIG, pela bolsa ao primeiro autor. À Indústria de Polpas e Conservas VAL Ltda., pelo auxílio na condução do experimento.

\section{REFERÊNCIAS}

ANDRADE, A. C.; FONSECA, D. M.; GOMIDE, J. A.; ALVAREZ V., V. H.; MARTINS, C. E.; SOUZA, D. P. H. Produtividade e valor nutritivo do capimelefante cv. Napier sob doses crescentes de nitrogênio e potássio. Revista Brasileira de Zootecnia, Viçosa, MG, v. 29, n. 6, p. 1589-1595, 2000.

BATAGLIA, O. C.; FURLANI, A. M. C.; TEIXEIRA, J. P. F.; FURLANI, P. R.; GALLO, J. R. Métodos de análise química de plantas. Campinas: Instituto Agronômico, 1983. 48 p. (Boletim Técnico, 78).

CARDOSO, E. A.; COSTA, J. T. A.; SOARES, I.; SILVA, R. M.; AGUIAR, A. V. M. Teores de nutrientes em folhas de goiabeira 'Paluma' em função da adubação mineral. Agropecuária Científica no Semiárido, Campina Grande, v. 6, n. 3, p. 28-31, 2010.

CARDOSO, E. A.; COSTA, J. T. A.; SOARES, I.; SILVA, R. M.; MARACAJÁ, P. B. Produtividade da goiabeira 'Paluma' em função da adubação mineral. Revista Verde, Mossoró, v. 6, n. 2, p. 149-153, 2011.

CAVAlCANTE, I. H. L.; SILVA, G. F.; CAVALCANTE, L. F.; SANTOS, D.; BECHMANNCAVALCANTE, M. Z. Composição mineral de folhas de goiabeira Paluma em função da adubação sulfato-nitrogenada. Revista Brasileira de Ciências Agrárias, Recife, v. 3, n. 1, p. 6-12, 2008.
CHETRI, K.; SANYAL, D.; KAR, P. L. Changes in nutrient element composition of guava leaves in relation to season, cultivar, direction of shoot, and zone of leaf sampling. Communications in Soil Science and Plant Analysis, Philadelphia, v. 30, n.1/2, p.121-128, 1999.

EMBRAPA. Empresa Brasileira de Pesquisa Agropecuária. Centro Nacional de Pesquisa de Solos. Sistema brasileiro de classificação de solos. Brasília: Embrapa SPI, 2006. 306 p.

FERREIRA, D. F. Sisvar: a computerstatisticalanalysis system. Ciência e Agrotecnologia, Lavras, v. 35, n.6, p. 1039-1042, 2011.

KUMAR, P.; PANDEY, R. M. Sampling for mineral content in leaves of guava cultivar 'Lucknow-49'. Scientia Horticulturae, Amsterdam, v.11, n. 2, p.163-174, 1979.

MACIEL, J. L.; DANTAS NETO, J. D.; FERNANDES, P. D. Resposta da goiabeira à lâmina de água e à adubação nitrogenada. Revista Brasileira de Engenharia Agrícola e Ambiental, Campina Grande, v.11, n. 6, p. 571-577, 2007.

MARSCHNER, M. G. Mineral nutrition of higher plants. $2^{\text {nd }}$ ed. London: Academic Press, 1995. 889 p.

NATALE, W. Diagnose da nutrição nitrogenada e potássica em duas cultivares de goiabeira (Psidium guajava L.), durante três anos. 1993. 149 f. Tese (Doutorado em Solos e Nutrição de Plantas) - Escola Superior de Agricultura Luiz de Queiróz, Universidade de São Paulo, Piracicaba, 1993.

NATALE, W.; BOARETTO, A. E.; PEREIRA, F. M. Effect of potassium fertilization in 'Rica' guava (Psidium guajava) cultivation. The Indian Journal of Agricultural Sciences, New Delhi, v. 66, n. 4, p. 201-207, 1996a.

NATALE, W.; BOARETTO, A. E.; PEREIRA, F. M. La fertilisation azotée du goyavier. Fruits, Montpellier, v. 49, n. 3, p. 205-210, 1994.

NATALE, W.; COUTINHO, E. L. M.; BOARETTO, A. E.; CENTURION, J. F. Resposta da goiabeira (Psidium guajava L.) cv. Paluma em formação à adubação fosfatada. Revista Brasileira de Fruticultura, Jaboticabal, v. 23, n. 1, p.92-96, 2001. 
NATALE, W.; COUTINHO, E. L. M.; BOARETTO, A. E.; PEREIRA, F. M.; OIOLI, A. A. P.; SALES, L. Nutrição e adubação potássica na cultura da goiabeira. Revista Brasileira de Ciênica do Solo, Viçosa, MG, v. 20, p. 247-250, 1996 b.

NATALE, W.; COUTINHO, E. L. M.; PEREIRA, F. M.; BOARETTO, A. E.; OIOLI, A. A. P.; SALES, L. Adubação nitrogenada na cultura da goiabeira. Revista Brasileira de Fruticultura, Jaboticabal, v. 17, n. 2, p. 7-15, 1995.

NATALE, W.; PRADO, R. M.; QUAGGIO, J. A.; MATTOS JÚNIOR, D. Guava. In: CRISÓSTOMO, L. A.; NAUMOV, A.; JOHNSTON, A. E. Fertilizing for high yield and quality tropical fruits of Brazil. Horgen/Switzerland: International Potash Institute, 2007. v. 1, p. 103-122.

OLIVEIRA, S. A. Análise foliar. In: SOUSA, D. M. G.; LOBATO, E. Cerrado: correção do solo e adubação. Brasília: EMBRAPA Informação Tecnológica, 2004. p. 245-256.

PEREIRA, F. M. Cultura da goiabeira. Jaboticabal: FUNEP, 1995. p. 32-41.

PEREIRA, F. M. Goiaba: Antecedentes, progresso e perspectivas. In: ALBUQUERQUE, A. C. S.; SILVA, A. G. Agricultura tropical: quatro décadas de inovações tecnológicas, institucionais e políticas. Brasília: Embrapa Informação Tecnológica, 2008. cap. 9 , p. 375-382.

QUAGGIO, J. A.; RAIJ, B. VAN; PIZA JÚNIOR, C. T. Frutíferas. In: RAIJ, B. VAN; CANTARELLA, H.; QUAGgiO, J. A.; FURLANI, A. M. C. Recomendações de adubações e calagem para o Estado de São Paulo. Campinas: IAC, 1997. p. 121-153. (Boletim Técnico, 100).

RAIJ, B. VAN; ANDRADE, J. C.;. CANTARELLA, H.; QUAGGIO, J. A. Análise química para avaliação da fertilidade de solo tropicais. Campinas: IAC, 2001. 285 p.
RAIJ, B. VAN; CANTARELLA, H.; QUAGGIO, J. A.; FURLANI, A. M. C. Recomendações de adubações e calagem para o Estado de São Paulo. Campinas: IAC, 1997. p. 8-13. (Boletim Técnico, 100).

ROZANE, E. D.; BRUGNARA, V.; SOUZA, H. A.; AMORIM, D. A. Condução, arquitetura e poda da goiabeira para 'mesa' e/ou 'indústria'. In: NATALE, W.; ROZANE, D. E.; SOUZA, H. A.; AMORIM, D. A. (Ed.). Cultura da goiaba: do plantio à comercialização. Jaboticabal: FCAV/FAPESP, 2009. v. 2. cap. 17 , p. 407-428.

SOUZA, H. A.; ROZANE, D. E.; AMORIM, D. A.; NATALE, W. Normas preliminares DRIS e faixas de suficiência para a goiabeira 'Paluma'. Revista Brasileira de Fruticultura, Jaboticabal, v. 35, n. 1, p. 282-291, 2013.

TERÁN, L.; MELÉNDEZ, I.; GARCÍA-AGUILAR, L.; ACUÑA, J. G.; URDANETA, M. Efecto de laaplicación de nitrógeno y potasio em el rendimento del cultivo de laguayaba (Psidium guajava L.). Revista de La Facultad de Agronomía(Luz), Maracaibo, v. 13, n. 4, p. 363-370, 1996.

VILELA, E. F.; BÜLL, L. T. Avaliação do crescimento de plantas de milho em função de doses de potássio e estresse hídrico. Revista Brasileira de Ciência do Solo, Viçosa, MG, v. 23, n. 2, p. 281-289, 1999.

VITTI, G. C. Avaliação e interpretação do enxofre no solo e na planta. Jaboticabal: FUNEP, 1989. 37p. 